\title{
Stress Corrosion Cracking of Ring Type Joint of Reactor Pipeline of a Hydrocracker Unit
}

\author{
P. Gore*, M. Sujata\#, S.K. Bhaumik ${ }^{\#}$ \\ * Maulana Azad National Institute of Technology, Department of Materials Science \& \\ Metallurgical Engineering, Bhopal 462051, INDIA \\ \#Council of Scientific and Industrial Research (CSIR), National Aerospace \\ Laboratories, Materials Science Division, Bangalore 560 017, INDIA
}

\begin{abstract}
Failure of a ring type joint (RTJ) of reactor pipeline of a hydrocracker unit has been reported. Cracks were noticed on the flange as well as the ring gasket of the RTJ during inspection following a periodic shutdown of the unit. These components of the RTJ were manufactured from stabilized grades of austenitic stainless steel, namely, type 321 and 347 respectively. Study showed that the failure of the RTJ components occurred by transgranular stress corrosion cracking (SCC). It was further established that formation of polythionic acid due to presence of $\mathrm{H}_{2} \mathrm{~S}$ in the process gas and $\mathrm{H}_{2} \mathrm{O}$ in the system was responsible for initiation of SCC in RTJ components. Detailed metallurgical investigation was carried out to identify the probable causes that could have been responsible for formation polythionic acid in the process gas.
\end{abstract}

Keywords: Ring type joint; stainless steels 347 and 321 ; transgranular fracture; SCC, polythionic acid

\section{Introduction}

Stress corrosion cracking (SCC) is one of the major contributors to the failures in petrochemical industries that deal with potentially aggressive chemical species. SCC is reported to be the principal mode of failure of plant equipment in oil industries, and accounts for about $25 \%$ of the total failures [1]. SCC results from the combined action of three factors, namely, sustained tensile stresses in the material, a corrosive medium (a chloride-bearing or hydrogen-sulphide environment) and elevated temperature. There are also other factors which affect the SCC mechanism in austenitic grade of stainless steels and these are $\mathrm{pH}$ of solution, stress level, microstructure, and the presence of chemical species such as elemental sulphur [2].

In view of their excellent corrosion resistance at moderate temperatures in combination with good mechanical properties, austenitic grades of stainless 
steels are extensively used in petrochemical industries. However, one of the major factors contributing to SCC failures in austenitic stainless steels is sensitization of the steel either during manufacture of the component or during service [3]. It is, therefore, a common practice to use stabilized grades of stainless steels to avoid sensitization and thus prevent SCC. In spite of this precautionary measure, failures do occur because of various reasons.

The present failure investigation is concerned with SCC of a ring type joint (RTJ) of reactor pipeline of a hydrocracker unit. The RTJ consisted of a circular flange with a groove, made of type 321 stainless steel, and a metallic gasket of oval cross section, made of type 347 grade stainless steel.

\section{The Failure}

As a part of inspection during periodic shutdown, all flange joints of reactor pipelines of a hydrocarker unit were subjected to dye penetrant inspection (DPI). During this time, a crack was noticed in the groove of the flange of a RTJ. The crack was found present on the entire circumference of the groove (Fig.1(a). DPI also revealed a circumferential crack over a sector of the ring gasket of the joint (Fig.1(b)).

The hydrocracker unit was in service for about 11 years at the time of failure. There were three periodic shutdowns of the unit prior to this failure and no abnormalities were reported in the joint during the earlier shutdowns. The recommended maximum working temperature and the pressure at the RTJ were $410-452^{\circ} \mathrm{C}$ and $191 \mathrm{~kg} / \mathrm{cm}^{2}$ respectively.

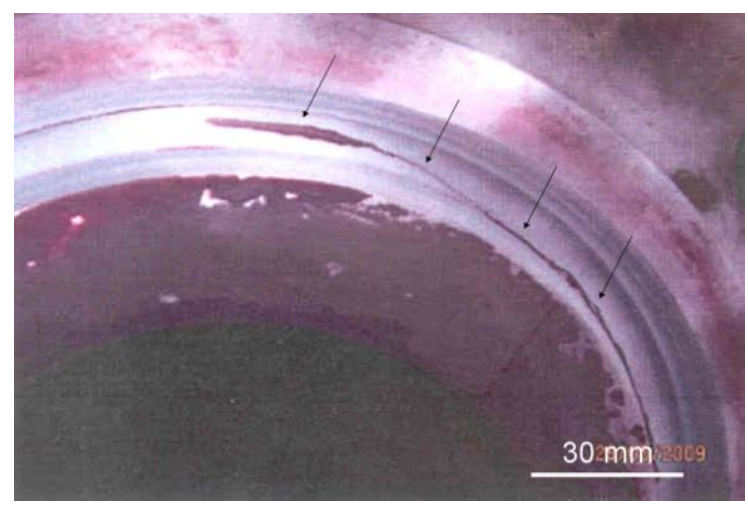

(a)

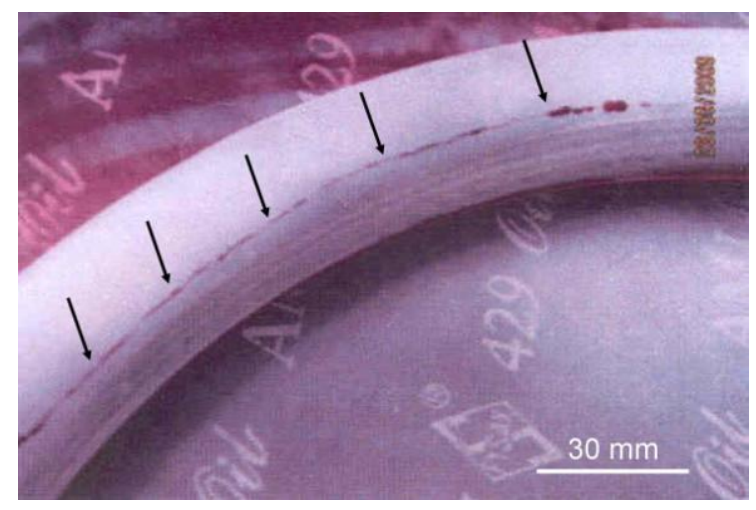

(b)

Figure 1 Photographs showing cracks (arrows) on (a) groove of the flange, and (b) ring gasket after DPI 


\section{Results of Laboratory Investigation}

\subsection{Visual and stereo-binocular examination}

Figure 2(a) shows the ring gasket of the RTJ. Examination revealed that the ring had developed a number of discrete cracks. These cracks were located on the inner side of the ring and all of them were oriented in circumferential direction (Fig.2(b-c)). Figure 3(a) shows a sector of the flange received for investigation. Visual examination showed presence of a number of cracks located all over the groove of the flange (Fig.3(b-d)).

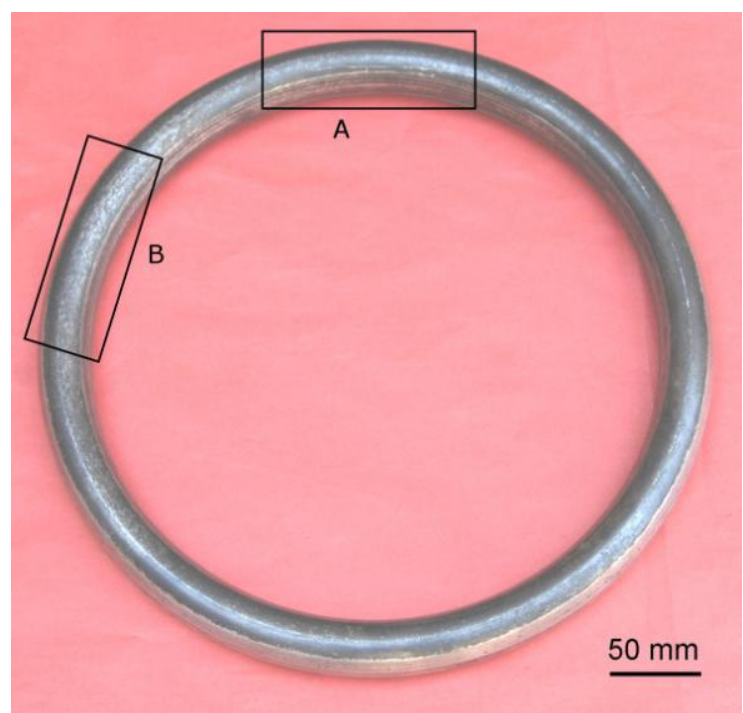

(a)

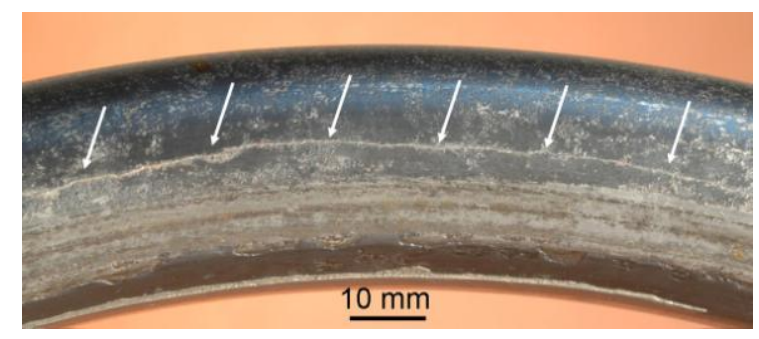

(b)

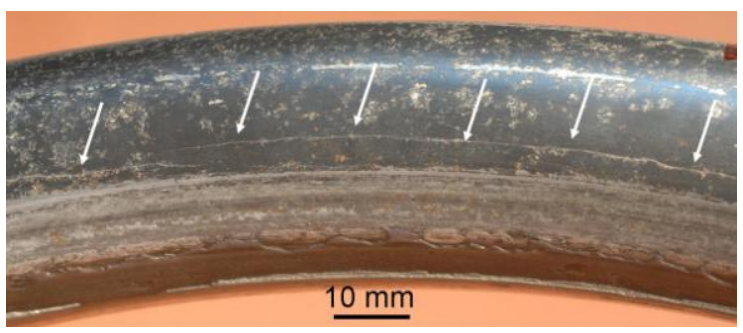

(b)

Figure 2 (a) Ring gasket, (b-c) close-up views of regions A and B respectively, marked in (a) showing cracks (arrows) in the circumferential direction

\subsection{Fractography}

A few of the cracks from the ring gasket as well as the flange of the RTJ were pulled open by providing suitable cuts and the resulting fracture surfaces were examined under stereo-binocular microscope. The fracture surfaces were found covered with firmly adherent corrosion products (Fig.4).

The crack surfaces shown in Fig. 4 were cleaned ultrasonically in acetone and they were examined under a scanning electron microscope (SEM). Fracture surfaces were found covered with a thick layer of oxides and/or corrosion products and hence, the micro-fractographic features were largely obliterated. SEM examination, however, showed presence of large number of secondary cracks on the fracture surfaces (Fig.5). Compositional analysis 
carried out by using Energy Dispersive X-ray (EDX) analyzer attached to the SEM revealed that the corrosion products consisted of oxides of iron and chromium, and sulphur in significant quantities (refer Table 1).

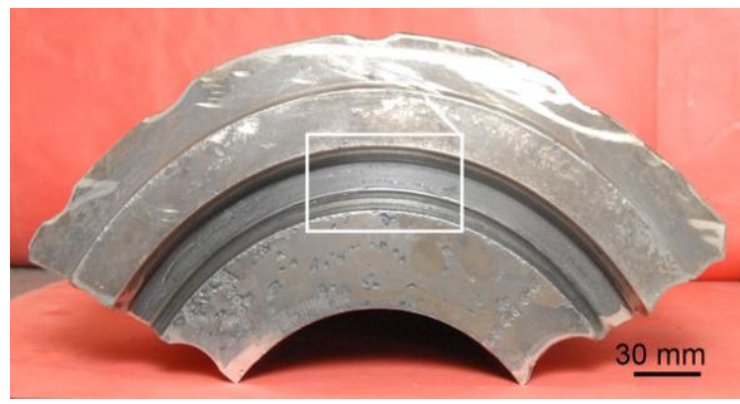

(a)

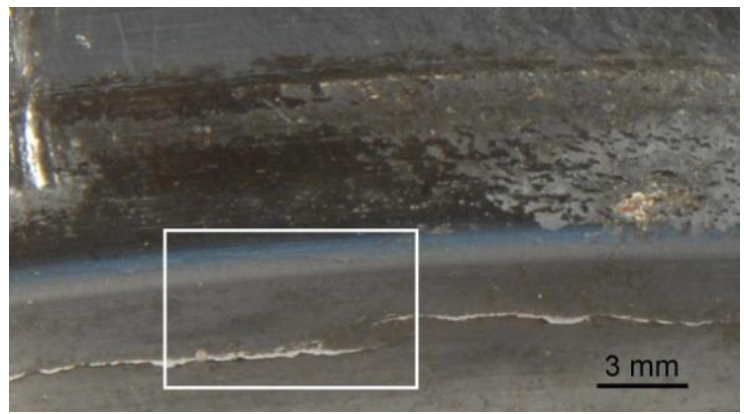

(c)

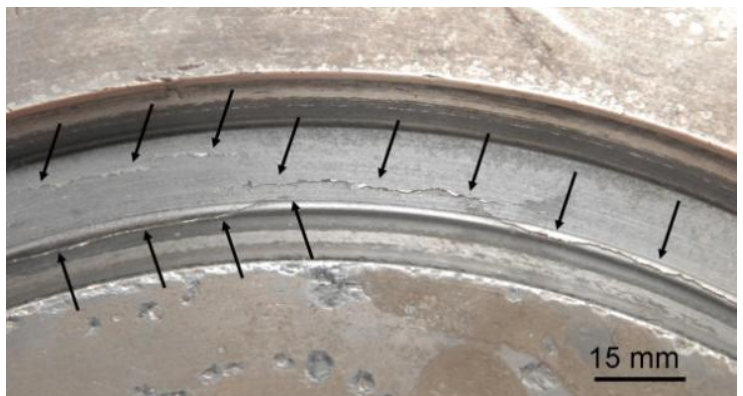

(b)

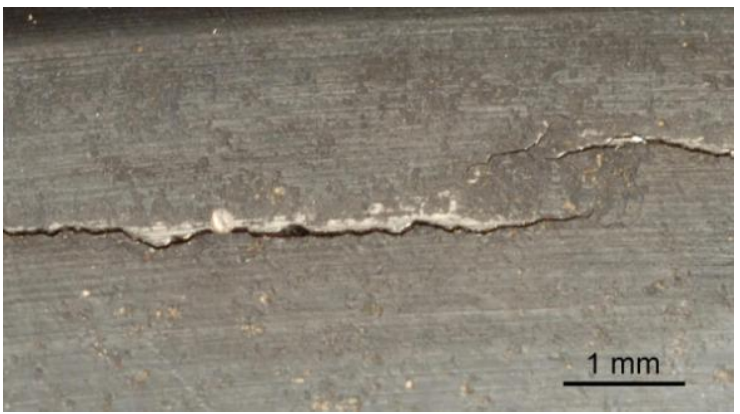

(d)

Figure 3 (a) a part of the flange of RTJ, (b) close-up view of the groove marked in (a) showing multiple cracks (arrows), (c) multiple cracks joining together, and (d) magnified view of the region marked in (c)

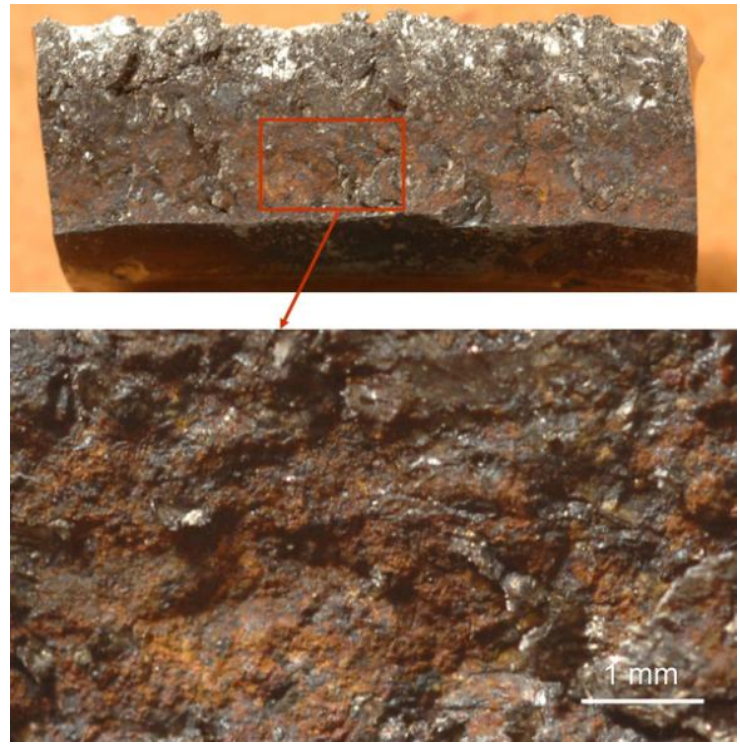

(a)
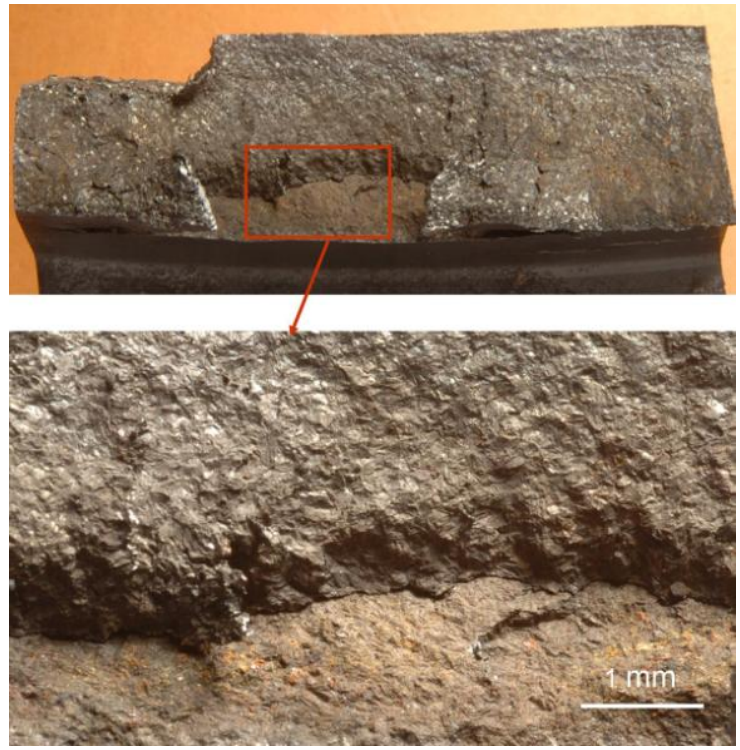

(b)

Figure 4 Fracture surfaces of (a) ring gasket, and (b) flange of the RTJ showing presence of a thick layer of oxides and/or corrosion products 


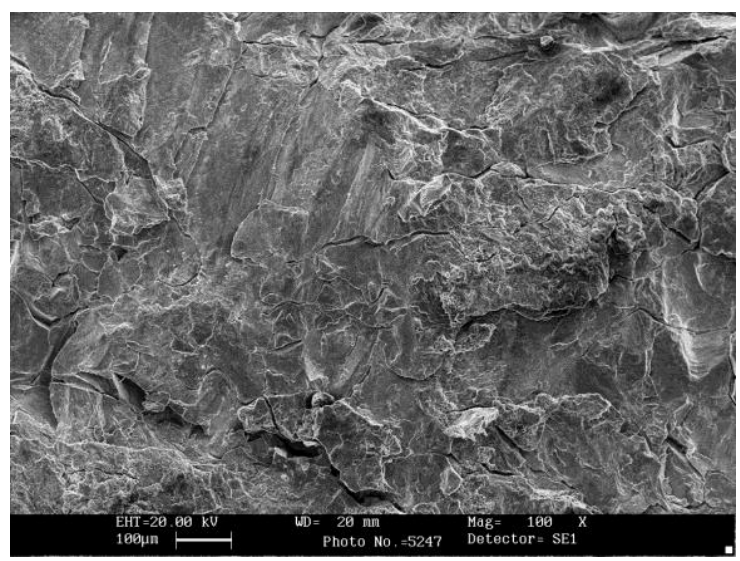

(a)

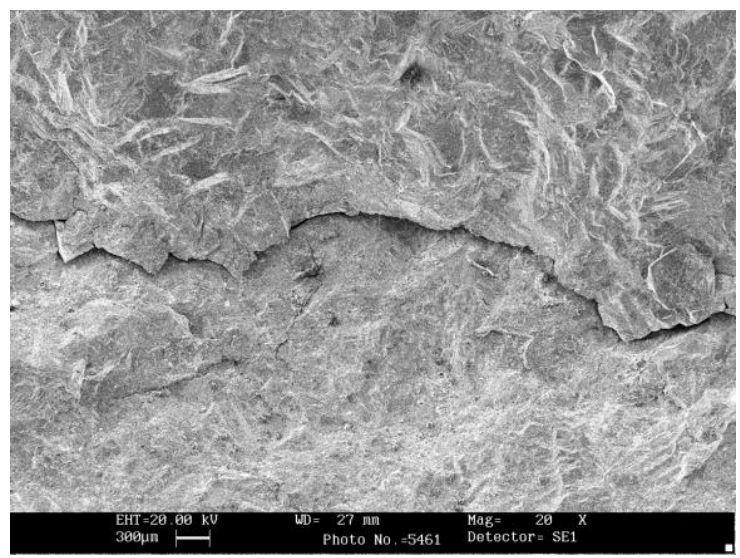

(b)

Figure 5 Scanning electron images of fracture surfaces of (a) ring gasket, and (b) flange of the RTJ showing obliteration of the micro-fractographic features due to corrosion

Table 1 Semi-quantitative compositional analysis of the corrosion products on the fracture surface and inside the propagating branching cracks; carried out by EDX analysis

\begin{tabular}{lcccccccc}
\hline \multirow{2}{*}{$\begin{array}{l}\text { Component / } \\
\text { location }\end{array}$} & \multicolumn{1}{l}{ Composition, wt.\% } \\
\cline { 2 - 10 } Ring Gasket & $\mathrm{O}$ & $\mathrm{Si}$ & $\mathrm{S}$ & $\mathrm{Cr}$ & $\mathrm{Mn}$ & $\mathrm{Ni}$ & $\mathrm{Ti}$ & $\mathrm{Fe}$ \\
On surface & 45.8 & 0.1 & 8.1 & 4.7 & 0.5 & 7.0 & - & 33.8 \\
Crack interior & 32.4 & 0.8 & 4.7 & 8.4 & 0.6 & 4.4 & - & 48.7 \\
\hline Flange & & & & & & & & \\
On surface & 28.0 & 0.4 & 13.9 & 8.0 & 0.6 & 5.1 & 0.4 & 43.6 \\
Crack interior & 24.8 & 0.4 & 3.2 & 11.4 & 1.1 & 3.3 & 0.5 & 55.3 \\
\hline
\end{tabular}

\subsection{Metallurgical examination}

Samples were cut from the cracked regions of the ring gasket and the flange for microstructural study. The surfaces along the transverse as well as longitudinal sections were prepared metallographically and examined in both etched and un-etched conditions. Aqua-regia was used for etching.

\subsubsection{Mode of crack propagation and microstructure}

Figure 6(a) shows the profile of the crack propagation path on the cross section of the ring gasket. The crack appeared to have originated on the 
surface, propagated progressively inside the material and finally, exited on the surface encompassing about one-fourth of the cross section. The magnified view of the crack near the surface is shown in Fig.6(b). Examination revealed multiple crack initiation at the surface and their propagation predominantly by transgranular mode, with extensive branching (Fig.7). Similar observations were made on the cracked flange as well, and these are summarized in Fig.8.

Figure 9 shows the microstructures of the ring gasket and flange material respectively. They were found to be consisted of twinned austenitic grains with uniformly distributed carbide particles. The materials were free from any metallurgical abnormalities such as sensitized structure.

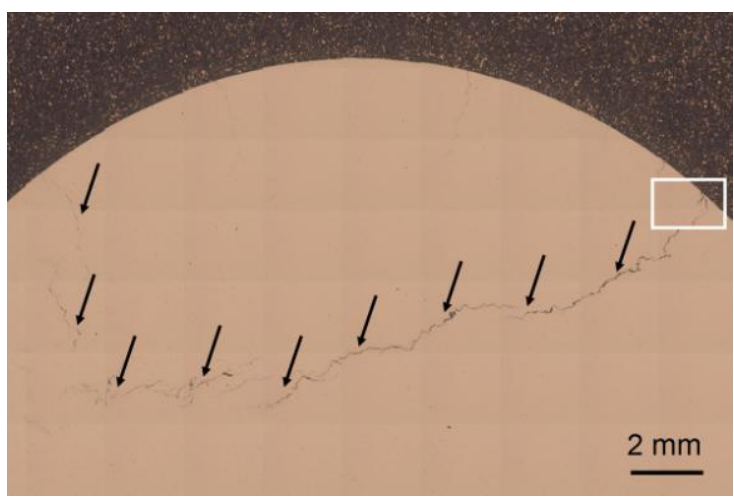

(a)

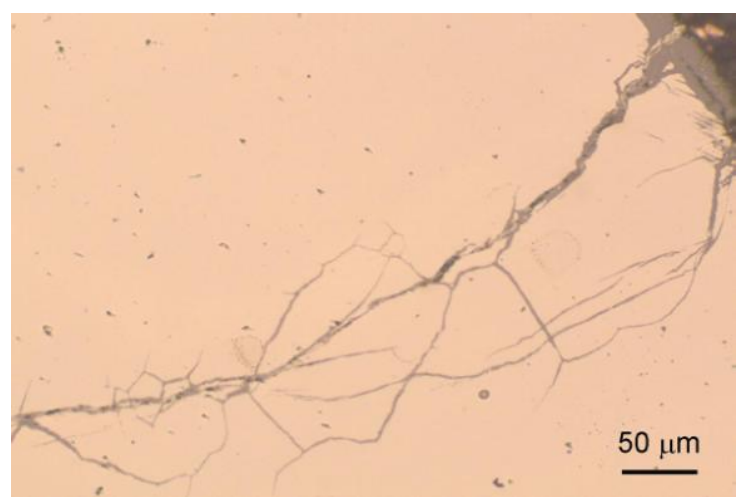

(b)

Figure 6 Cross section of the ring gasket showing (a) crack profile and propagation path, and (b) extensive crack branching

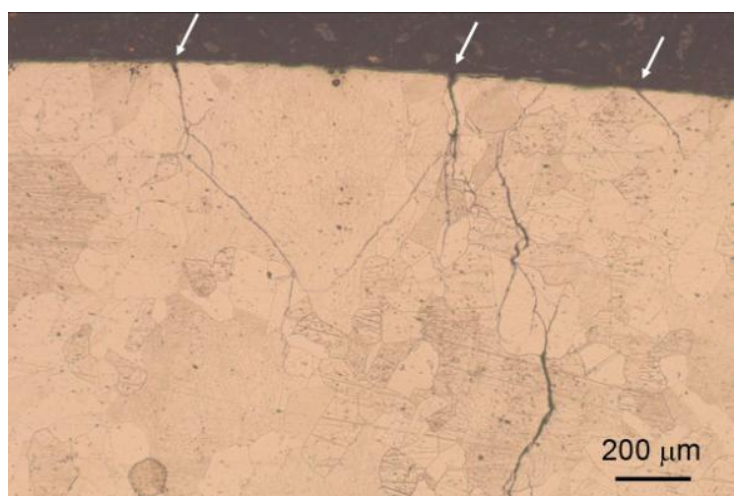

(a)

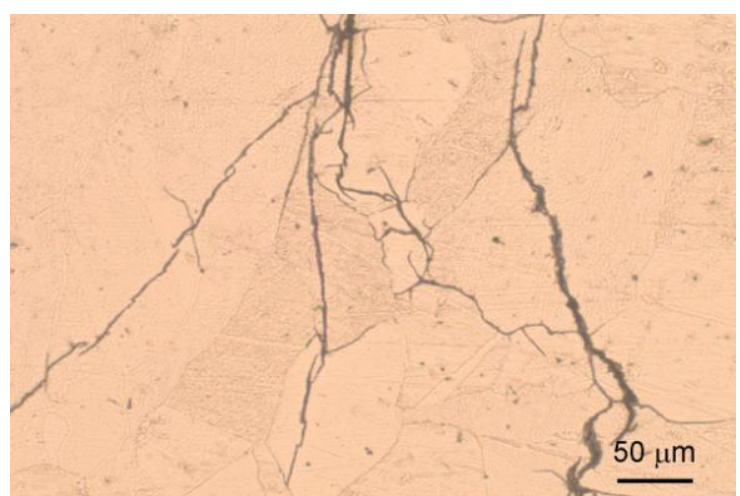

(b)

Figure 7 Etched microstructures showing transgranular mode of crack propagation in the ring gasket of the RTJ: (a) multiple crack initiation on the surface (arrows), and (b) inside the material 


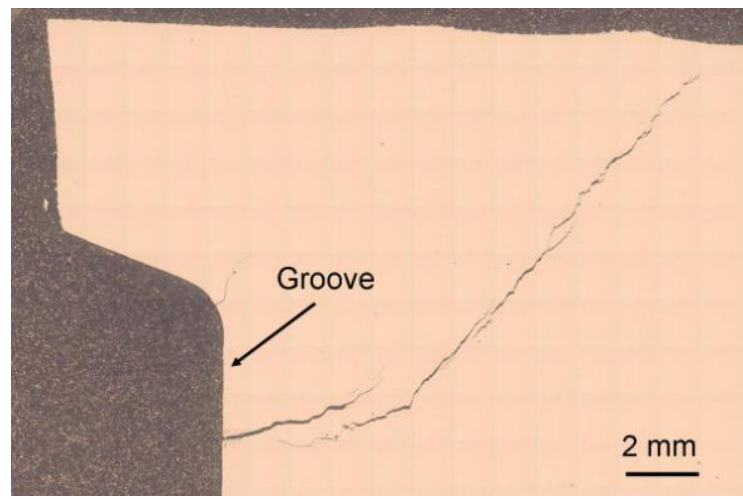

(a)

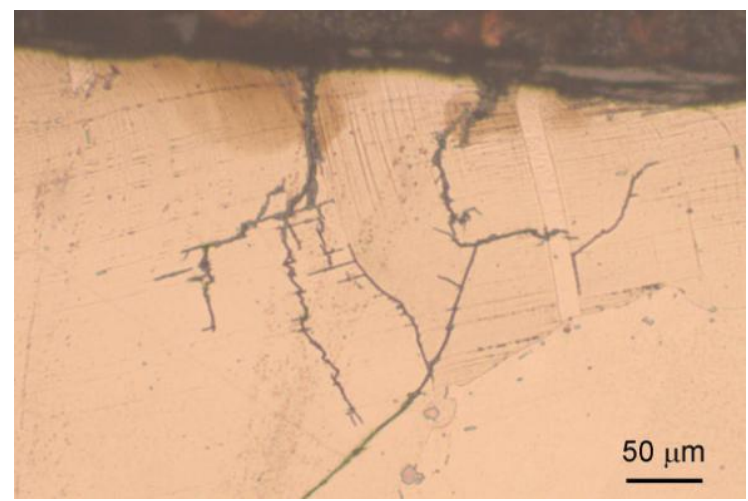

(c)

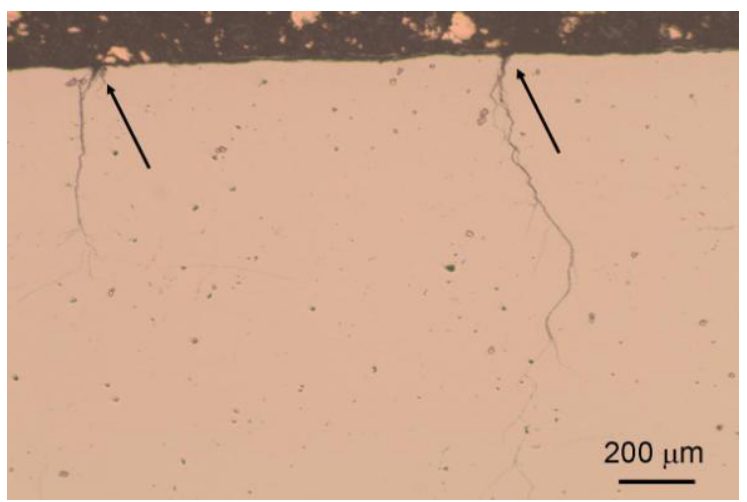

(b)

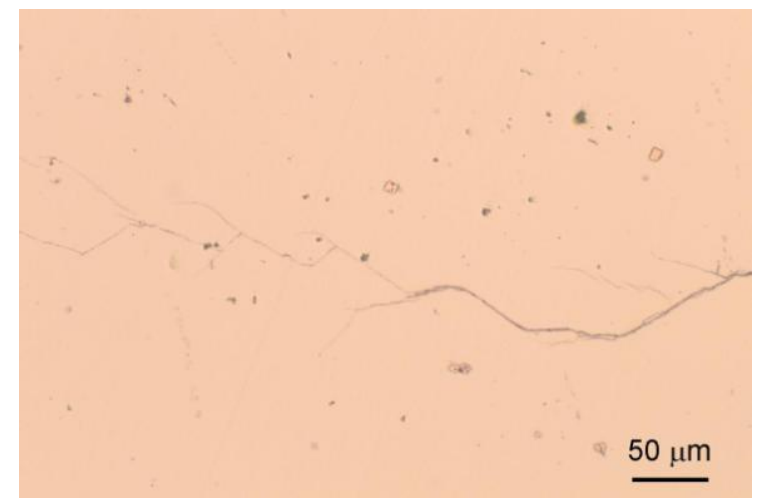

(d)

Figure 8 Crack initiation and propagation in the groove of the flange: (a) overall crack profile and crack propagation path, (b) multiple crack initiation on the surface (arrows), and (c) and (d) transgranular crack propagation near the surface and in the bulk material respectively

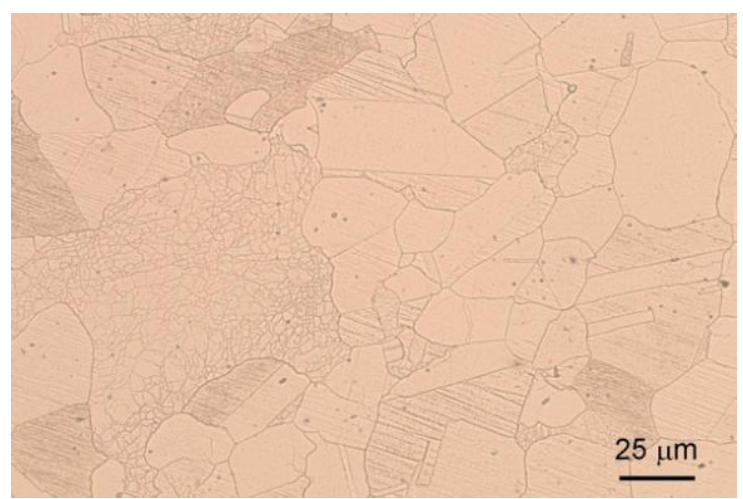

(a)

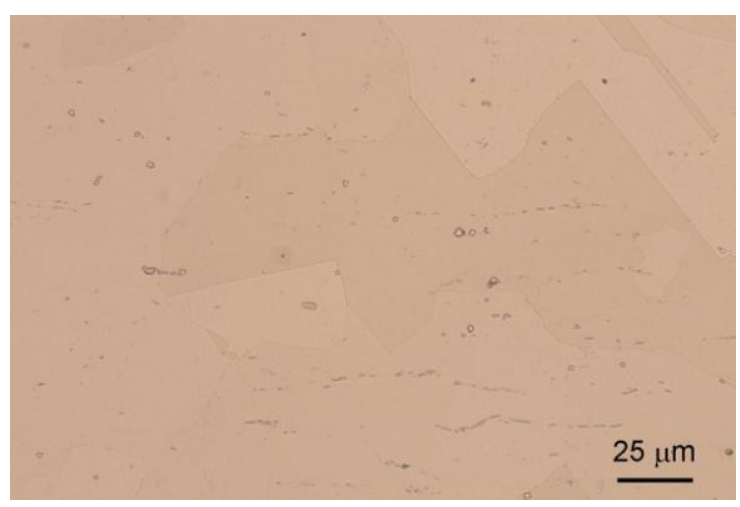

(b)

Figure 9 Optical microstructure of (a) ring gasket, and (b) flange material consisting of austenite grains, with uniformly distributed carbide particles 


\subsubsection{Corrosion products}

Figure 10(a) shows a propagating crack in the bulk material of the ring gasket. It can be seen that the crack is filled with corrosion products. EDX analysis showed that the corrosion products consisted of mainly oxides of iron and chromium, and sulphur in quantities as high as 5 wt\% (Fig.10(b), Table 1). The cracks in the flange of the RTJ were also found filled with corrosion products of similar composition (Table 1 ).

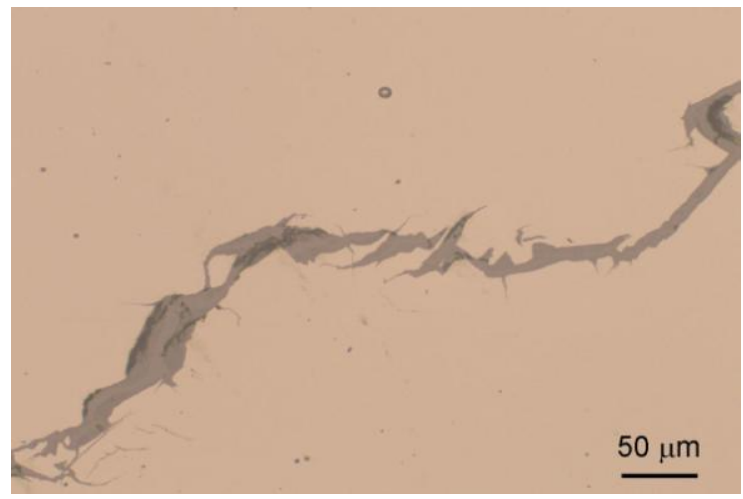

(a)

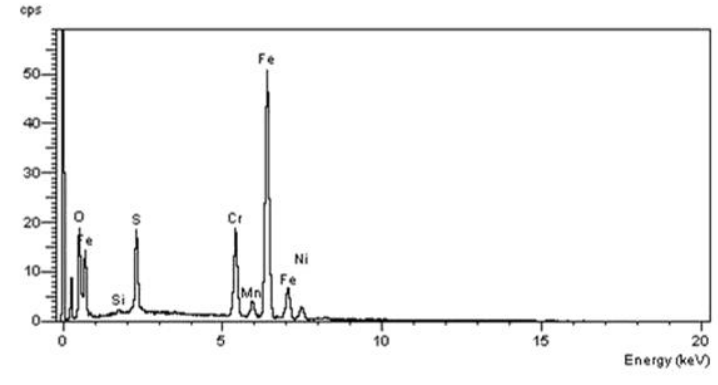

(b)

Figure 10 (a) optical micrograph showing corrosion products within a propagating crack, and (b) EDX spectrum of the corrosion products

\subsubsection{Hardness and chemical composition}

Hardness measurements were carried out on the ring and flange material using a Vickers microhardness tester at a load of $500 \mathrm{~g}$. The hardness values were in the range 159-190 and 138-172 HV respectively for the ring and flange material respectively.

The composition of the material of construction of the ring and the flange was determined by optical emission spectroscopy. The results obtained are given in Table 2. Analysis confirmed that the ring and flange were manufactured using type 347 and type 321 grade stainless steels respectively.

\section{Analysis of failure}

Optical and scanning electron microscopy studies revealed presence of numerous cracks in the ring gasket and the flange of the RTJ. The cracks had emanated from the surfaces, and there was extensive branching of the 
cracks as they propagated inside the material. Microstructural study also showed that the propagation of the cracks was predominantly by transgranular manner. Compositional analysis showed that the corrosion products present on the crack surfaces consisted of mainly oxides of iron and chromium with significant quantities of sulphur. Based on these evidences, it can be concluded that the cracking of the RTJ components was by stress corrosion cracking (SCC) mechanism.

Table 2 Spectro-chemical analysis of ring and flange material

\begin{tabular}{|c|c|c|c|c|c|c|c|c|c|}
\hline \multicolumn{10}{|c|}{ Composition, wt\% } \\
\hline C & $\mathrm{Mn}$ & $\mathrm{Si}$ & $\mathrm{S}$ & $P$ & $\mathrm{Ni}$ & $\mathrm{Cr}$ & $\mathrm{Nb}$ & $\mathrm{Ti}$ & $\mathrm{Fe}$ \\
\hline \multicolumn{10}{|c|}{ Specification of SS 347} \\
\hline $\begin{array}{l}0.08 \\
\max \end{array}$ & $\begin{array}{l}2.00 \\
\max \end{array}$ & $\begin{array}{l}1.00 \\
\max \end{array}$ & $\begin{array}{l}0.030 \\
\max \end{array}$ & $\begin{array}{l}0.045 \\
\max \end{array}$ & $\begin{array}{l}9.0- \\
13.0\end{array}$ & $\begin{array}{l}17.0- \\
19.0\end{array}$ & $\begin{array}{l}10 \times \\
C \text { min }\end{array}$ & - & Balance \\
\hline \multicolumn{10}{|c|}{ Ring gasket } \\
\hline 0.02 & 1.45 & 0.53 & 0.002 & 0.03 & 9.69 & 18.0 & 0.53 & - & Balance \\
\hline \multicolumn{10}{|c|}{ Specification of SS 321} \\
\hline $\begin{array}{l}0.08 \\
\max \end{array}$ & $\begin{array}{l}2.00 \\
\max \end{array}$ & $\begin{array}{l}1.00 \\
\max \end{array}$ & $\begin{array}{l}0.030 \\
\max \end{array}$ & $\begin{array}{l}0.045 \\
\max \end{array}$ & $\begin{array}{l}9.0- \\
12.0\end{array}$ & $\begin{array}{l}17.0- \\
19.0\end{array}$ & - & $5 \times C$ & Balance \\
\hline \multicolumn{10}{|c|}{ Flange } \\
\hline 0.07 & 1.21 & 0.62 & 0.009 & 0.014 & 9.42 & 17.9 & - & 0.56 & Balance \\
\hline
\end{tabular}

Generally, stress corrosion cracking occurs in a component when the following three conditions are met simultaneously.

(a) Sustained tensile stress - cannot be avoided in an assembly like RTJ.

(b) Material susceptibility to corrosion - can be minimized by appropriate selection of material.

(c) Presence of corrosion species in the environment - can be minimized by appropriate process control.

The materials used for the fabrication of the ring gasket and the flange are SS 347 and SS 321 respectively. These are stabilized grades of austenitic stainless steel and are extensively used in applications of the present kind. Microstructural examination and hardness survey revealed that the steels were used in annealed condition. The materials of construction did not have any metallurgical abnormalities. Hence, any deficiency in the material leading to SCC can be ruled out. 
In view of the above and the fact that cracking occurred only on the process side of the components, the role of corrosion species in promoting SCC assumes significance. In aggressive environment and at elevated temperature, SCC in stainless steels can occur if corrosion species such as chlorides, caustic, sulphides and polythionic acids are present in the environment in sufficient quantities [4-6]. In this present case, absence of chlorine and alkali metals, and presence of sulphur in the corrosion products indicate that the most probable mechanism of failure in RTJ components was sulphide SCC.

The mode of crack propagation during sulphide SCC in stainless steels depends on whether or not the environment contains $\mathrm{O}_{2}$ and/or $\mathrm{H}_{2} \mathrm{O}$. If these species are not present, the crack propagation generally takes place by intergranular mode. Otherwise, $\mathrm{H}_{2} \mathrm{~S}$ present in the process gas is known to react with $\mathrm{O}_{2}$ and $\mathrm{H}_{2} \mathrm{O}$ leading to formation of polythionic acids of type $\mathrm{H}_{2} \mathrm{~S}_{x} \mathrm{O}_{y}$. It is reported $[4,5]$ that polythionic acids result in transgranular cracking in non-sensitized stainless steels, especially when they are used in annealed condition. In view of crack propagation predominantly by transgranular mode in the present case, inference is drawn that formation of polythionic acid in the process gas was responsible for the SCC failure of the RTJ components.

SCC failure by polythionic acid in petrochemical industries is a concern and hence, appropriate preventive measures are generally incorporated in the system so that the process gas containing sulphur and $\mathrm{H}_{2} \mathrm{~S}$ is free from $\mathrm{O}_{2}$ and $\mathrm{H}_{2} \mathrm{O}$ as far as possible. In spite of this, the intrusion of these species in the system can occur because of one or more of the following reasons.

(a) Improper shutdown resulting in exposure of components to atmosphere.

(b) Oxygen and water originating from steam or wash water used to free components of hydrocarbons before inspection or steam purges and water sprays used during regeneration of catalyst systems.

(c) Ineffectiveness of the catalytic beds in removal of oxygen from the process gas during cracking.

Examination of the records confirmed that there were no abnormalities in the process gas in the period between the previous and present shutdown of the hydrocracker unit. Based on this, the possibility (c) leading to the SCC can be ruled out. Hence, it is logical to conclude that improper shutdown of the unit in the previous occasion was responsible for intrusion of $\mathrm{O}_{2}$ and $\mathrm{H}_{2} \mathrm{O}$ in the system, which in turn were responsible for formation of polythionic acid on the system. 


\section{Conclusions}

(a) The ring gasket and the flange of the RTJ have failed by sulphide SCC.

(b) Investigation showed that the crack propagation during SCC was by transgranular mode. This mode was favoured over intergranular mode of crack propagation due to formation of polythionic acid in the system.

(c) Evidences suggest that improper shutdown of the hydrocracker unit in the previous maintenance was responsible for intrusion of $\mathrm{O}_{2}$ and $\mathrm{H}_{2} \mathrm{O}$ in the system.

\section{Acknowledgements}

The authors gratefully acknowledge the contribution of M. Madan at various stages of investigation including sample preaparation, metallography and hardness measurements.

\section{References}

1. G.R. Lobley, Stress corrosion cracking: Cases in refinery equipment, $2^{\text {nd }}$ International conference on environment-induced cracking of metals (2008), Elsevier, Amsterdam, p.401.

2. Metals Handbook. Vol.13: Corrosion, $9^{\text {th }}$ ed. American Society for Metals, 1987. p.1276.

3. H.H. Horowitz, Chemical studies of polythionic acid stress corrosion cracking, Corros. Sci. 23 (1983) 353-362.

4. H. M. Tawancy, Failure of hydrocracker heat exchanger tubes in an oil refinery by polythionic acid-stress corrosion cracking, Eng. Fail. Anal. 16 (2009) 2091-2097.

5. Metals Handbook. Stress corrosion cracking, Vol.10: Failure Analysis and prevention, $8^{\text {th }}$ ed. American Society for Metals, 1975. p. 205-217.

6. A.N. Delavar, M. Shayegani and A. Pasha, An investigation of cracking causes in an outlet RTJ flange in ISOMAX unit, Case studies in Engineering Failure Analysis. 1 (2013) 61-66 